\title{
РАССМОТРЕНИЕ В АДМИНИСТРАТИВНОМ ПРОЦЕССЕ ТРЕБОВАНИЙ О ВОЗМЕЩЕНИИ ВРЕДА: ЗАРУБЕЖНЫЙ ОПЫТ
}

\begin{abstract}
Аннотация. Статья посвящена анализу зарубежного опыта нормативного закрепления возможности рассмотрения в рамках административного судопроизводства при оспаривании решений, действий (бездействия) административных органов требования о возмещении вреда. На примере таких стран, как Аргентина, Армения, Болгария, Грузия, Индия, Испания, Италия, Китай, Латвия, Литва, Португалия, Украина, Франция, Швейцария, Эстония автор приходит к выводу, что в большинстве из них тем или иным образом закреплено правило, предусматривающее, что вопросы, связанные с возмещением вреда, причиненного решениями, действиями (бездействием) административных органов и должностных лии, рассматриваются совместно с делом о признании их незаконными, то есть, по сути, в рамках одного административного процесса. При написании статьи, в первую очередь, были использованы методы анализа, синтеза, системный и сравнительно-правовой метод. На основе анализа нормативных правовых актов ряда зарубежных государств автором делается вывод о необходимости дополнения Кодекса административного судопроизводства Российской Федерации положениями, предусматривающими возможность рассмотрения в порядке административного судопроизводства соответствующих требований о возмещении вреда, причиненного оспариваемыми решениями, действиями (бездействием) в срере административных и иных публичных правоотношений.

Ключевые слова: административный прочесс, зарубежный опыт, возмещение вреда, КАС РФ, Аргентина, Армения, Болгария, Грузия, Испания, Франция

Abstract. The paper contains the analysis of the foreign experience of normative consolidation of the possibility to consider the cases of recourse against decisions, actions, or inactions of administrative bodies, related to the claims for indemnification, within administrative proceedings. The author studies the cases of Argentina, Armenia, Bulgaria, Georgia, India, Spain, Italy, China, Latvia, Lithuania, Portugal, Ukraine, France, Switzerland, and Estonia, and comes to the conclusion the most of them use the provision allowing considering the claims for indemnification for damage caused by decisions, actions, or inactions of administrative bodies or authorities together with the cases about declaring them illegal, i.e. within the same administrative process. The methodology is based on the methods of analysis and synthesis, the system and comparativelegal methods. The author analyzes the statutory instruments of foreign states and comes to the conclusion about the necessity to amend the Administrative Court Procedure Code of the Russian Federation with the provisions stipulating the possibility to consider the claims for indemnification of damage caused by the disputed decisions, actions, or inactions in the sphere of administrative or other public legal relations within administrative proceedings.
\end{abstract}

Key words: Administrative Court Procedure Code of the Russian, compensation of harm, foreign experience, administrative proceedings, Argentina, Armenia, Bulgaria, Georgia, Spain, France.

П рактика применения недавно вступившего в силу ключевого административно-процессуального нормативного правового акта Кодекса административного судопроизводства Российской Федерации свидетельствует о необходимости его дальнейшего совершенствования.

В частности, одной из пока не разрешенных проблем является отсутствие закрепления в нем возможности рассмотрения в рамках административного судопроизводства при оспаривании решений, действий (бездействия) органов государственной власти, органов местного самоуправления, иных органов, организаций, наделенных отдельными государственными или иными публичными полномочиями, должностных лиц, государственных или муниципальных служащих требования о возмещении вреда, причиненного оспариваемыми решениями, действиями (бездействием).
Соответственно, в настоящее время у административного истца отсутствует процессуальная возможность в рамках рассмотрения в суде одного дела добиться, как признания оспариваемого решения, действия (бездействия) незаконным, так и получить возмещение вреда, возникшего в результате такого нарушения.

С учетом изложенной проблемы представляется актуальным провести анализ зарубежного опыта, касающегося права стороны непосредственно в рамках административного судебного разбирательства, либо внесудебного административного процесса заявлять требования о возмещении вреда, причиненного оспариваемыми актами, решениями, действиями (бездействием).

Сразу оговоримся, что в законодательстве зарубежных государств нередки случаи прямого закрепления такой правовой возможности. Вместе с 


\section{Административное и муниципальное право 4 (100) 2016}

тем, следует обратить внимание и на второй вариант - часто встречается ее косвенное закрепление, а именно, в административно-процессуальных законах содержатся специальные нормы об ответственности административных органов и должностных лиц за принятие незаконных актов управления, за неправомерные действия (бездействие).

Итак, рассмотрим конкретные примеры.

\section{Аргентина}

Правовое регулирование рассматриваемых вопросов в этой стране, которая по форме государственного устройства является федерацией, производится на уровне ее субъектов. Например, согласно статье 12 Закона провинции Буэнос-Айрес от 17.10.1997 № 12008 «Об административном процессе» [1] в рамках разрешения спора в административно-процессуальном порядке могут быть заявлены, в частности, следующие требования:

- о полном или частичном аннулировании административных актов индивидуального или общего характера;

- о восстановлении или признании нарушенных прав или интересов;

- о возмещении причиненного ущерба.

\section{Армения}

Рассматриваемым вопросам посвящен Раздел VII «Ответственность за ущерб, причиненный администрированием» Закона Республики Армения от 18.02.2004 «Об основах администрирования и административном производстве» [2].

Часть 1 статьи 95 указанного нормативного правового акта предусматривает, что ущерб, причиненный лицам вследствие осуществляемого административными органами администрирования, подлежит возмещению в соответствии с положениями настоящего раздела.

Как установлено статьями 96 и 97 закона, возмещение ущерба по общему правилу не осуществляется до тех пор, пока правовой акт, действие или бездействие, которыми лицу причинен ущерб, не признаны в установленном порядке неправомерными. При этом, возмещение ущерба осуществляется посредством устранения или возмещения денежными средствами последствий, возникших в результате администрирования.

Интересно, что первоначально требование о возмещении ущерба должно быть предъявлено в административный орган, в результате администрирования которого причинен ущерб, в течение 3 лет с того момента, когда лицо узнало или обязано было знать о причиненном ему ущербе, но не позднее чем по истечении 10 лет с момента совершения того действия, или допущения бездействия, или вступления в силу правового акта, которым ему причинен ущерб (статьи 100, 101).

Данное требование первоначально рассматривается и разрешается в административном порядке. Вместе с тем, лицо, понесшее ущерб, в случае отклонения административным органом заявления полностью или частично или нерассмотрения им заявления может обжаловать это как в вышестоящий административный орган, так и в суд (статья 102).

\section{Болгария}

Вопросам, связанным с возмещением ущерба стороне административного процесса, посвящена глава 11 Административно-процессуального кодекса Болгарии «Производство по возмещению ущерба» [3].

Согласно статье 203 Кодекса, иски о возмещении ущерба, причиненного гражданину или юридическому лицу незаконными актами, действиями или бездействием административных органов и должностных лиц, подлежат разрешению в соответствии с положениями данной главы (то есть, в рамках административного судопроизводства). По тем же правилам разрешаются вопросы, об имущественной ответственности государства и муниципалитетов за причиненный ущерб.

В соответствии со статьями 204 и 205 указанного Кодекса, иск о возмещении ущерба может быть предъявлен, как после признания недействительным (аннулирования) соответствующего административного акта, так и совместно с заявлением об обжаловании административного акта, но до первого заседания по делу (при этом, все недостатки такого заявления должны быть устранены не позднее этого заседания).

Если ущерб причинен недействительным (аннулированным) административным актом, противоправность деяния устанавливается судом, в который предъявлен иск о возмещении вреда. Незаконность действия или бездействия также устанавливается судом, в который предъявлен иск о возмещении вреда.

Иск о возмещении ущерба, предъявляется к лицу или органу, чей незаконный акт, действие или бездействие повлекли ущерб.

Статья 206 Кодекса предусматривает, что по требованию одной из сторон или по усмотрению суда требования о возмещении ущерба могут быть выделены в отдельное производство, если рассмотрение этого требования будет препятствовать разбирательству по основному административному делу.

Рассмотрение указанного требования продолжается в том же суде после вступления в силу судебного акта по вопросу о признании недействительным (аннулировании) соответствующего административного акта. 
Важным также является положение, содержащееся в статье 207 Кодекса, согласно которому, если производство по делу об оспаривании административного акта приостанавливается или прекращается, соответственно приостанавливается или прекращается разбирательство по вопросу о возмещении ущерба, соединенное с основным процессом. Производство по иску о возмещении вреда также подлежит прекращению, если заявление о признании административного акта недействительным (аннулировании) будет отклонено.

\section{Грузия}

Подпункт «в» пункта 1 статьи 2 Административно-процессуального кодекса Грузии [4] устанавливает общую обязанность административного органа по возмещению вреда, причиненного изданием незаконного административно-правового акта или совершением какого-либо иного действия.

Кроме того пункт 6 статьи $21^{3}$ данного Кодекса устанавливает особые правовые возможности и условия для возмещения ущерба, причиненного вследствие виновного деяния контролирующего органа, но применительно к ограниченному кругу лиц - в отношении предпринимателей.

\section{Индия}

В пункте «г» статьи 3 Закона Индии от 17.02.1985 «Об административных трибуналах» [5] содержится понятие «жалобы о возмещении ущерба», которые подаются в рамках административного процесса в случае причинения заявителю вреда какими - либо административными актами. Статья 20 данного закона содержит также некоторое уточнение относительно такого рода жалоб, так, например, часть 1 данной статьи устанавливает необходимость в определенных случаях использования заявителем всех иных имеющихся средств правовой защиты, перед тем как подать жалобу о возмещении вреда.

\section{Испания}

Согласно части 1 статьи 67 Закона Испании от 01.10.2015 № 39/2015 «Об общей административной процедуре в государственной администрации» [6], заинтересованные лица (стороны) вправе инициировать отдельный процесс об имущественной ответственности, только если специально не предусматривается право на подачу заявления в рамках административной процедуры.

Право на подачу такого заявления действует в течение года после наступления события или совершения действия, являющегося основанием для возмещения вреда, либо следствием которого стало нарушение прав и законных интересов лица. В случае причинения физического или психического вреда лицу, этот срок начинает исчисляться с мо- мента излечения либо установления масштаба наступивших последствий.

\section{Италия}

Согласно части 1 статьи 30 Административнопроцессуального кодекса Италии, утвержденного законодательным декретом от 02.07.2010 № 104 [7], по общему правилу является возможной вместе с административным иском подача иска о возмещении ущерба. Часть 2 данной статьи предусматривает, что такой иск может быть подан в случае неоправданного причинения вреда в результате осуществления административной деятельности незаконным образом, либо ее неосуществления, если она является обязательной.

В соответствии с частью 3 статьи 30 указанного выше нормативного правового акта иск о возмещении ущерба за нарушение прав и законных интересов может быть подан в течение ста двадцати дней с момента, когда имело место применение соответствующих административных мер, если ущерб был причинен непосредственно в результате их применения. При определении размеров компенсации суд производит оценку всех обстоятельств дела и в любом случае исключает убытки, которых можно было бы избежать при обычной осмотрительности или использовании лицом предусмотренных законом инструментов защиты.

\section{Китай}

Статья 67 Закона Китайской Народной Республики от 04.04.1989 «Об административной процедуре» [8] устанавливает, что гражданин, юридическое лицо или любая другая организация, которым причинен ущерб нарушением их прав и законных интересов посредством издания конкретного административного акта, имеют право на компенсацию. Если гражданин, юридическое лицо или любая другая организация подает самостоятельное заявление о возмещении ущерба, дело в приоритетном порядке должно рассматриваться в административном органе. Лицо, не согласное с решением административного органа, вправе обратиться с иском в народный суд.

\section{Латвия}

Согласно статье 92 Закона Латвии от 25.10.2001 «Об административном процессе» [9], каждое лицо имеет право требовать адекватную компенсацию за финансовые убытки или ущерб, в том числе, нематериальный, причиненный ему посредством издания административного акта, либо совершения конкретных действий административным органом. При этом, согласно статье 97 данного закона, при определении размеров и условий возмещения имущественного ущерба и личного вреда, приме- 
няются принципы гражданского права, если иное не предусмотрено законом.

\section{Литва}

Как следует из подпункта 3 пункта 1 статьи 15 Закона Литвы от 14.01.1999 «Об административном судопроизводстве» [10], к компетенции административных судов прямо отнесены дела о возмещении ущерба, причиненного незаконными действиями субъектов публичного управления.

При этом в данной норме содержится ссылка на статью 6.271 Гражданского кодекса Литвы, посвященную ответственности за ущерб, причиненный незаконными действиями государственных и муниципальных органов власти [11].

\section{Португалия}

Согласно статье 16 Административно-процессуального кодекса Португалии от 07.01.2015 [12], органы государственной администрации в соответствии с законодательством, несут ответственность за ущерб, причиненный при осуществлении ими своей деятельности. Пункт 2 статьи 68 данного Кодекса устанавливает правовые возможности для применения норм гражданского права в административном процессе.

\section{Украина}

Часть 2 статьи 21 Кодекса административного судопроизводства Украины [13] предусматривает, что требования о возмещении вреда, причиненного противоправными решениями, действиями или бездействием субъекта властных полномочий или другим нарушением прав, свобод и интересов субъектов публично-правовых отношений, рассматриваются административным судом, если они заявлены в одном производстве с требованием решить публично-правовой спор. В противном случае, требования о возмещении вреда рассматриваются судами в порядке гражданского или хозяйственного судопроизводства.

Таким образом, в рассматриваемом Кодексе требования о возмещении вреда рассматриваются административным судом в соответствии с правилами подсудности нескольких связанных между собой требований

\section{Франция}

К компетенции административных судов во Франции изначально отнесены отдельные категории гражданских дел, например, о продаже и аренде недвижимого имущества, находящегося в государственной собственности, о государственных контрактах.

Кроме того, в соответствии с положениями статей L741-2 и L741-3 Кодекса административной юстиции Франции [14] административные суды рассматривают дела о возмещении ущерба, причиненного оскорбительными или клеветническими выступлениями лиц в административном процессе.

Статьей L551-16 данного Кодекса предусмотрено, что административные суды рассматривают встречные иски о возмещении убытков и процентов, основанных на первоначальных требованиях, по срочным вопросам, связанным с заключением государственных контрактов.

Кроме того, в административном процессе Франции активно применяется гражданско-правовой институт астрента, как способа воздействия на должника, призванный принудить его выполнить судебное решение об исполнении основного обязательства. Он представляет собой обязанность выплаты, в дополнение к обязанности исполнить основное обязательство, увеличивающейся на определенную сумму за каждый день просрочки исполнения основного обязательства (статьи L911-3 - L911-8 Кодекса административной юстиции Франции).

\section{Швейцария}

Гарантии возмещения ущерба, причиненного административными органами, установлены, в частности, пунктом 4 статьи 55 Союзного закона Швейцарии от 20.12.1968 (в редакции по состоянию на 01.01.2015) «Об административной процедуре» [15].

\section{Эстония}

Подпунктом 4 пункта 1 статьи 5 Административно-процессуального кодекса Эстонии [16] прямо предусмотрено полномочие административного суда взыскать компенсацию за вред, причиненный в публично-правовых отношениях.

Кроме того, ряд положений рассматриваемого нормативного правового акта раскрывает отдельные процессуальные вопросы, касающиеся такого требования. Например, если предметом спора является деятельность регионального структурного подразделения или должностного лица ответчика, причиненный ею вред или ее последствия, то жалоба подается по месту нахождения структурного подразделения или по месту службы должностного лица (пункт 1 статьи 7); жалоба по административному делу может содержать требование о возмещении вреда, причиненного в публично-правовых отношениях (жалоба о возмещении вреда) (подпункт 4 пункта 1 статьи 37); при заявлении требования о денежном возмещении, в жалобе должен быть указан размер возмещения, а в случае требования о возмещении за неимущественный вред, а также в случае, если определение размера имущественного вреда является невозможным или необоснованно затруднительным для заявителя, он может не указывать в жалобе размер возмещения и ходатайство- 
вать о справедливом возмещении не усмотрение суда (пункт 2 статьи 38); жалоба о возмещении вреда или компенсационная жалоба может быть подана в течение трех лет со дня, когда податель жалобы узнал или должен был узнать о вреде и причинившем его лице либо о последствиях административного акта или действия, устранения которых он требует, однако, такая жалоба не может быть подана по истечении десяти лет со дня издания административного акта, обусловившего вред или последствия, либо правообразующего акта, совершения действия или объявления решения, вынесенного при осуществлении правосудия (пункт 4 статьи 46).

Интересным является также положение, закрепленное в пункте 1 статьи 206 Кодекса, согласно которому в качестве заявителя жалобы о возмещении вреда, причиненного нарушением административного договора может выступать административный орган, являющийся стороной такого договора или представляющий ее, а ответчиком - физическое лицо или юридическое лицо частного права.

Таким образом, на основе анализа нормативных правовых актов ряда зарубежных государств, можно сделать вывод о том, что в большинстве из них тем или иным образом закреплено правило, предусматривающее, что вопросы, связанные с возмещением вреда (как материального, так и морального), причиненного актами, решениями, действиями (бездействием) административных органов и должностных лиц, рассматриваются совместно с делом о признании их незаконными (одновременно, либо в течение определенного времени по его завершении), то есть, по сути, в рамках одного административного процесса (судебного или внесудебного).

Поскольку зачастую конечный правовой интерес административного истца состоит именно в получении возмещения вреда, причиненного соответствующим нарушением, именно такое правовое регулирование способствует обеспечению эффективной защиты прав субъектов административных правоотношений.

Представляется, что и в действующем Кодексе административного судопроизводства Российской Федерации также необходимо предусмотреть возможность рассмотрения в порядке административного судопроизводства требований о возмещении вреда, причиненного оспариваемыми решениями, действиями (бездействием) в сфере административных и иных публичных правоотношений.

\section{Библиография:}

1. Ley № 12008 de la Provincia de Buenos Aires.

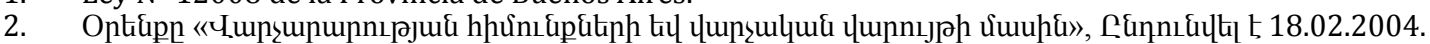

3. Административно-процесуален кодекс.

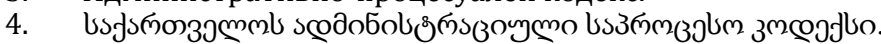

5. The Administrative Tribunals Act, 1985.

6. Ley № 39/2015, de 1 de octubre 2015, del Procedimiento Administrativo Común de las Administraciones Públicas // Boletín Oficial del Estado. 02.10.2015. № 236.

7. Decreto Legislativo 2 luglio 2010, № 104.

8. Administrative Procedure Law of the People's Republic of China.

9. Administratīivā procesa likums // «Latvijas Vēstnesis». 14.11.2001. № 164(2551).

10. Administraciniu Bylu Teisenos Istatymas 1999 m. sausio 14 d. № VIII-1029.

11. Civilinio kodekso patvirtinimo, įsigaliojimo ir igyvendinimo.

12. Decreto-Lei № 4/2015, de 7 de janeiro de 2015 - Código do procedimento administrativo (Novo).

13. Кодекс адміністративного судочинства України.

14. Code de justice administrative.

15. Loi fédérale sur la procédure administrative du 20 décembre 1968 (Etat le 1er janvier 2015).

16. Halduskohtumenetluse seadustik.

\section{References (transliterated):}

1. Ley № 12008 de la Provincia de Buenos Aires.

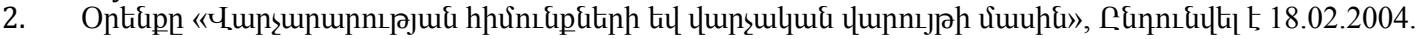

3. Administrativno-protsesualen kodeks.

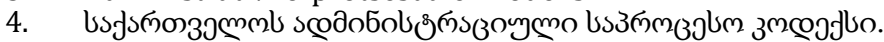

5. The Administrative Tribunals Act, 1985.

6. Ley № 39/2015, de 1 de octubre 2015, del Procedimiento Administrativo Común de las Administraciones Públicas // Boletín Oficial del Estado. 02.10.2015. № 236.

7. Decreto Legislativo 2 luglio 2010, № 104 .

8. Administrative Procedure Law of the People's Republic of China.

9. Administratīiā procesa likums // «Latvijas Vēstnesis». 14.11.2001. № 164(2551).

10. Administracinių Bylų Teisenos İstatymas 1999 m. sausio 14 d. № VIII-1029.

11. Civilinio kodekso patvirtinimo, isigaliojimo ir igyvendinimo.

12. Decreto-Lei № 4/2015, de 7 de janeiro de 2015 - Código do procedimento administrativo (Novo).

13. Kodeks administrativnogo sudochinstva Ukraïni.

14. Code de justice administrative.

15. Loi fédérale sur la procédure administrative du 20 décembre 1968 (Etat le 1er janvier 2015).

16. Halduskohtumenetluse seadustik. 